\title{
EXPERIMENTAL CONSOLIDATION WORKS IN RAMMED EARTH WALLS: THE CASE OF THE BAÑUELO IN GRANADA (SPAIN)
}

\author{
J.M. López-Osorio ${ }^{1, *}$, P. Bel-Anzué ${ }^{2}$ \\ ${ }^{1}$ University of Malaga, Málaga, Spain - lopezosoriojm@gmail.com \\ ${ }^{2}$ University of Granada, Granada, Spain - pedro.bel.anzue@ gmail.com
}

Commission II - WG II/8

KEY WORDS: Bañuelo, Arab bath, Rammed earth, Earth construction, Consolidation, Additives

\begin{abstract}
:
Between 2015 and 2018, different restoration works were carried out on the dividing walls of the Bañuelo in Granada. They affected rammed earth, masonry and brick fabrics of different chronological periods, corresponding to medieval structures (12th-15th centuries), Modern Age repairs (16th-18th centuries) and contemporary restoration works conducted by F. Prieto-Moreno and L. Torres Balbás (20th century). In this article are presented the works carried out on the west dividing wall, which separate the Arab bath from the garden of the adjoining house. This fabric corresponds to a recent chronology and is not related to the founding fabrics of the Andalusian building; this fact has allowed the development of experimental methodologies avoiding any alteration on structures of a high historical value. Nevertheless, this wall preserves a layered structure of repairs or restorations of Modern and Contemporary Age, which has been factored in the consolidation works. Accordingly, the intervention has not been limited to a strict preservation or a volumetric reintegration of the rammed earth fabric, but aims to offer a range of solutions according to the state of conservation of the structures and the erosion level of the surfaces, on the basis of a previous laboratory tests. Consequently, the conservation works present different intervention techniques and surface coating treatments, which facilitate the execution and contribute to the legibility and the integration of the intervention in the general context of the building.
\end{abstract}

\section{INTRODUCTION}

1.1 The Bañuelo in Granada: constructive history and restoration projects

The Arab bath of the Walnut or Bañuelo $\left(37^{\circ} 10^{\prime} 42.8^{\prime \prime} \mathrm{N}\right.$ $\left.3^{\circ} 35^{\prime} 35.2^{\prime \prime} \mathrm{W}\right)$, is located in the current quarter of the Albaicín, on the right bank of the Darro river, in front of the Nasrid palaces of the Alhambra, in Granada. The building occupies a $380 \mathrm{~m}^{2}$ plot and presents the characteristic Andalusian bath floor plan. It is organised according to a series of connected spaces: relaxation room, changing room, cold room, warm room, and hot room; this last one housed the steam bath and is located just next to the furnace, the boiler and the service room in which the wood was stored (Orihuela, López-Osorio, 2019). Today, this space has lost its vault and is currently uncovered (Figure 1). From the 16th century, in the Castilian period, many repair and maintenance works were carried out, due to the building continued being used as a bath by the Morisca population. During the following centuries, the building changed its use, housing a public laundry and a dwelling. In 1918, after being declared as a National Monument, a recovery process of the building began, which culminated in the first restoration works led by Leopoldo Torres Balbás (1927-28), architect-director of the Alhambra. In the second half of the 20th century, new works were carried out, among which should be highlighted those conducted by Francisco Prieto-Moreno (1955, 1972 and 1975), as well as others that affected the bath structures, as those by Rafael Rodríguez Sáez (1989- 95) and José Manuel López-Osorio (2005-2006 and 2015-18) (Orihuela, López-Osorio, in press). Our research describes some of the works carried out during the last intervention, in particular those developed on the dividing wall on the west side of the service room.

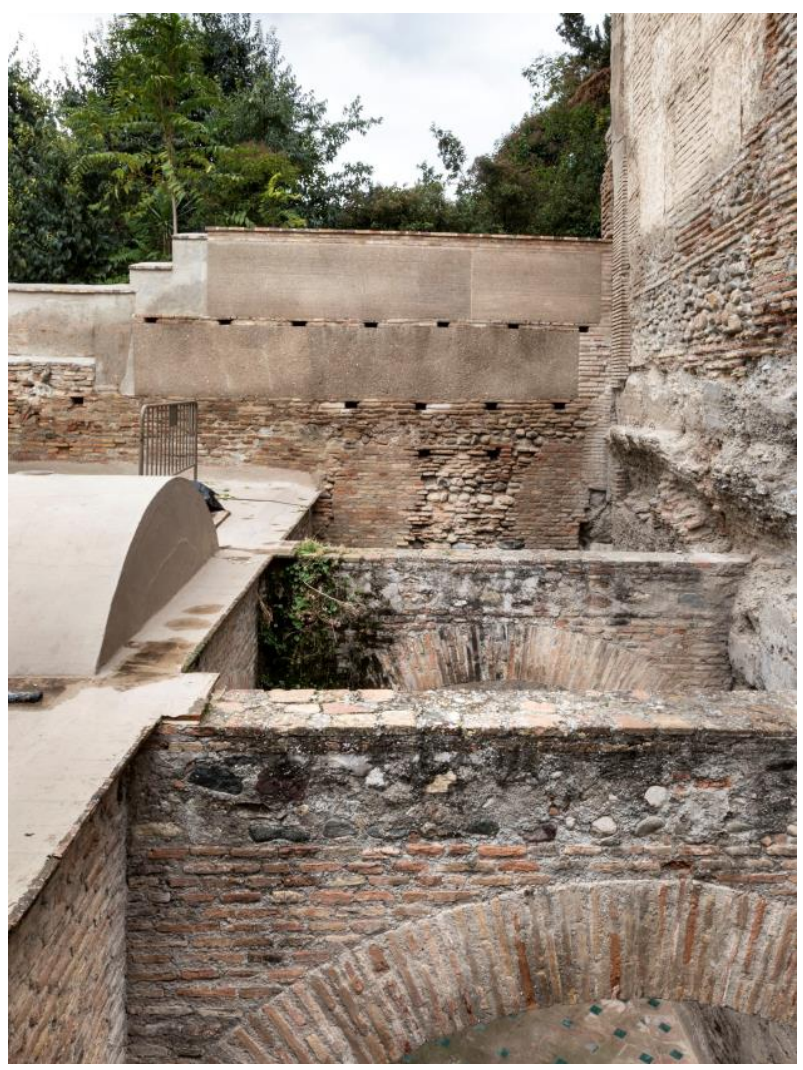

Figure 1. Overview of the service room of the Bañuelo. At the bottom: west dividing wall. Photograph: Cristina García-Zarza.

* Corresponding author 
The material and constructive typology of the fabrics present in the Bañuelo indicates a direct relationship with the period of its construction. The founding structure is mainly built by $60-65$ $\mathrm{cm}$ thick lime concrete walls that support solid brick vaults. The repair works of the Modern Age (16th-18th centuries), carried out with brick and masonry fabrics, were executed on the dividing walls, especially on those adjoining with buildings and plots of the northern sector. During the restoration work carried out in the 20th century, the added fabrics were built using solid bricks, many of which are reused medieval bricks. Among the works conducted by Torres Balbás, some of the vaults were partially reconstructed, and underpinning and repair works were executed on the dividing walls of the service room. This space was also intervened by Prieto-Moreno (Orihuela, López-Osorio, in press).

\subsection{The rammed earth fabric on the context of the building}

As indicated in the previous section, founding fabrics of the bath are made of lime concrete. This was a common procedure in the hydraulic buildings from the Nasrid period, as this kind of fabric provides the walls with a high structural strength, cohesion and surface hardness; all of them are essential conditions to support the weight and the thrust of the vaults and also the high steam concentration on the wet rooms, in the case of the baths. However, the rammed raw earth that is the subject of this research is not part of these structures, since it appears on the high levels of the dividing wall that enclose the building to the west. According with its constructive characteristics, this fabric could have been built on the 19th century, while many urban spaces of the Albaicín neighbourhood, in Granada, were transformed into cármenes, a traditional Grenadian house linked to an orchard garden.

Before the last restoration works (2015-18), the $50-55 \mathrm{~cm}$ thickness rammed earth wall presented two sections of $85 \mathrm{~cm}$ high each one, separated by two courses of solid bricks, below which a series of putlog holes appeared every $90 \mathrm{~cm}$; its function was to host the wooden stays in which the formwork is supported. The lower section presented also a course of bricks with putlog holes on its base, that was the finishing of a masonry and brick fabric probably built on Modern Age, although it features too the repairs done during the restorations of the 20th century. This masonry structure rests on the medieval lime concrete fabric, which corresponds to the original bath construction. The rammed earth wall is finished off on its northern side by a brick buttress that runs attached to the wall of the building located on this side (Figure 2).

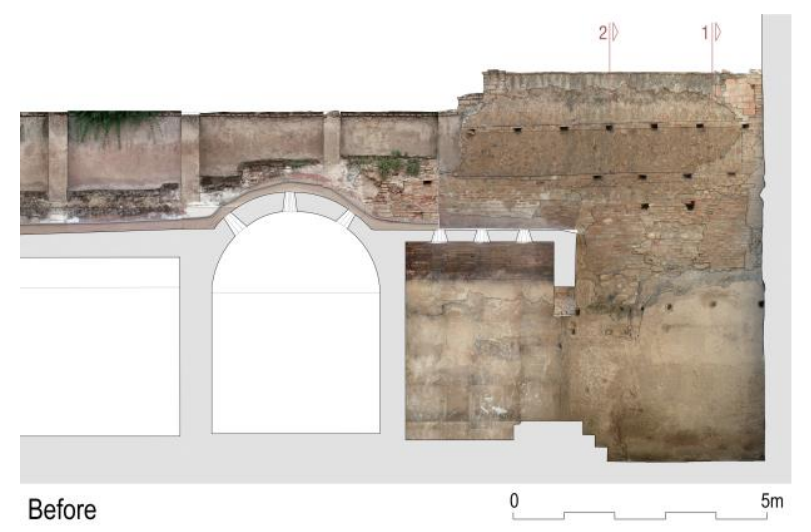

\section{METHODOLOGY, OBJECTIVES AND DEFINITION OF INTERVENTION CRITERIA}

The general methodology of the project begins with a phase of preliminary studies that is based on the analysis of the history of the construction of this building (Mileto, Vegas, 2017); that is, it considers all the repairs and restorations previously carried out, which have been described above.

During the different restoration works carried out on the dividing walls of the building, conducted from 2015 to 2018 , both paramental analysis and archaeological follow up were developed. These activities are essential to contextualise the intervention on the rammed earth fabric located on the walls, which is the aim of this research.

The preliminary studies are complemented with the development of a laboratory testing programme and a technicalscientific study, which consisted in a constructive and material characterization of the existing wall, constituting a direct support to the execution work. On-site testing was performed with the objective of accurately defining not only the composition of the masses that would be used for the intervention, but also the different commissioning application techniques. Moreover, one of the priority objectives of this intervention was to treat this wall as a real prototype to realise test and trials, which reinforces the experimental nature of the project. These works were developed with the support and expert advice of the technical staff of the Conservation and Protection Service of the Alhambra and Generalife, who was the promoter of the works.

As the rammed earth fabric of the west wall presented different levels of degradation (Figures 7 and 9), the consolidation works demanded two clearly differentiated techniques. The fabric presented in some parts a significant loss in mass, normally at the upper level and the top of the wall; in this case, it was necessary to reintegrate the missing volume. It was carried out by the formwork and rammed techniques. In other parts of the wall, a partial loss of material due to surface erosion or holes at middle or lower levels was observed.

These are situations that required punctual or superficial reintegration, as do not allow the execution of the rammed earth technique because the vertical ramming is not possible, or it is difficult to settle the formworks. So, in these cases, the consolidation was executed through filling with or application of a surface coating.

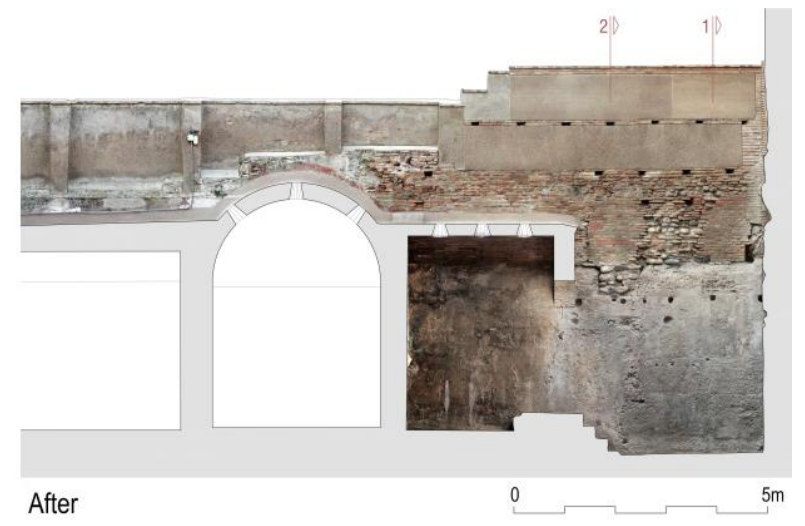

Figure 2. Elevation of the west dividing wall of the Bañuelo. State before and after the consolidation works (section pl. 1-2 marked). 


\section{PREVIOUS LABORATORY TESTS FOR THE EVALUATION OF THE EFFICACY OF NATURAL ADDITIVES FOR EARTH STABILIZATION}

Laboratory tests were carried out prior to the start of the in-situ intervention to improve the stability and durability of earth specimens. To achieve these objectives during the formulation phase of the replacement material, there are only two ways to proceed: add additives or balance the granulometry of the materials that make it up, to achieve maximum compactness, and avoiding the presence of intergranular voids according to the Fuller or Bolomey granulometric curve. This second path was ruled out in the case of the intervention in the Bañuelo wall, since it would have involved the alteration of the original grain size, generating too abrupt a textural variation in the general context of the restoration work. The use of additives is a traditional practice; however, the use of synthetic consolidants is a controversial procedure due to the deterioration produced by ultraviolet radiation exposure, losing its effectiveness 8-10 years after the first application, which requires periodic retreatments, which further decreases their effectiveness, since new applications are carried out on deteriorated layers. These treatments also have reduced reversibility because they penetrate the capillary network and it is difficult to completely remove them, even if solvents and poultices are used for extraction. Likewise, alkoxysilanes, such as ethyl silicate, which are applied on calcareous substrates, do not adhere to carbonates, so their consolidating effect is quite poor, forming retraction cracks during drying.

Therefore, this research has focused on the use of natural additives and traditional recipes (Vissac et al., 2012) that have been used worldwide to improve the behaviour and durability of earth constructions. The tests carried out in the laboratory have started with the choice of a earth similar to that of the rammed earth wall to be used, to which the natural additives listed below were added: lime paste, ash, prickly pear juice (pectic acid), oxides with acacia acid, linseed oil, straw and manure. In the case of the latter two, the tests were carried out both in the dry state and in the aerobic and anaerobic fermented state, using fermentation times of 10 and 17 days.

The earth chosen to carry out the test pieces was extracted from the so-called Alhambra Formation, in a location in the Darro Valley $\left(37^{\circ} 10^{\prime} 47.4^{\prime \prime} \mathrm{N} \quad 3^{\circ} 34^{\prime} 54.5^{\prime \prime W}\right)$, located $1 \mathrm{~km}$ from Bañuelo, to ensure a similarity with the materials that were originally used in the construction of the rammed earth wall. The properties of the earth with which the specimens were formed were described by Elert et al. (2019). Due to the large number of additives tested and the significant volume of samples necessary to carry out the investigation, a small test tube $(4 \times 4 \times 12 \mathrm{~cm})$ was used, sieving the soil to be tested to remove the particles that could not pass through the sieve 10 $\mathrm{mm}$. The elimination of inert gravels and stones was assumed, considering that the increase in the proportion of clays and silts would accelerate the consequences of the effects of deterioration applied in the tests, presenting values that, despite not being the real ones of the rammed earth wall, they are significant to compare between them and evaluate the efficacy of the additives to be studied.

The research was aimed at comparing how additives affect soil samples, performing standardized tests of: workability, simple compression, flexural traction, compactness by ultrasound, surface hardness with Shore C durometer, surface cohesion of particles by means of the "Scotch Tape Test", Durability to water immersion, capillary absorption-desorption, humidity retention by hygrometer (Esbert et al., 1997) and colour variation according to CIEDE2000 (Sharma et al., 2005). Despite the wide spectrum of proportions and additives analysed, the results of the laboratory tests carried out did not show a significant difference according to the type of additive, or depending on the form of aerobic or anaerobic fermentation, or according to the fermentation time to which they were subjected. Likewise, the test specimens tested documented almost identical mechanical, hydric and surface cohesion behaviours, except in the case of the addition of lime and linseed oil where very significant improvements were detected. Consequently, these products were considered suitable for in situ testing.

The laboratory tests were developed independently and in isolation, so that each test piece was only affected and / or altered by a single test. During the development of the tests it was necessary to have an active attitude of interpretation and repetition of tests. As it was a weak and heterogeneous material, it was common to obtain non-representative discordant values. The reality of the work is, in addition, more complex, since the degradation to which a material is subjected is the result of the combination of different simultaneous and dynamic actions. The research carried out is therefore presented as a first approach that will require further analysis in the face of the specific conditions of a given climate, orientation and exposure.
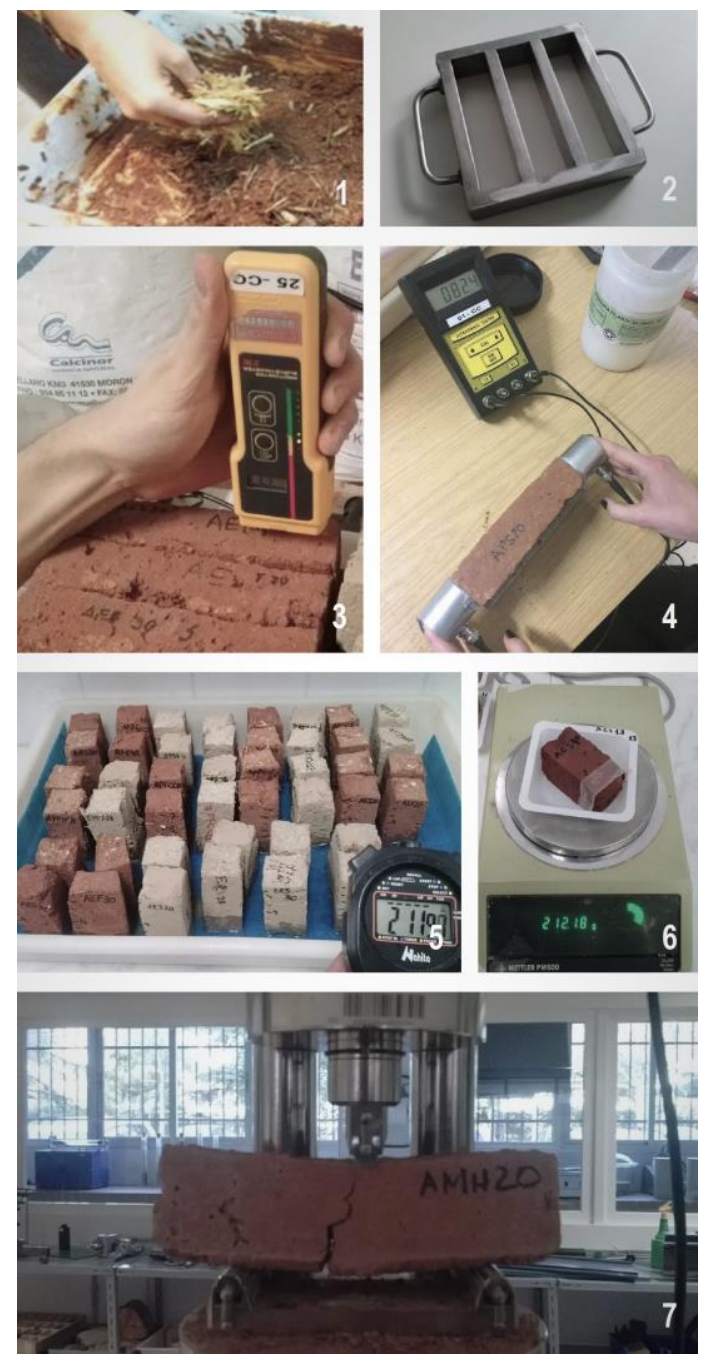

Figure 3. Some of the standardized tests of: 1-2. Workability; 3 . Humidity retention; 4. Compactness by ultrasound;

5-6. Capillary absorption-desorption; 7. Flexural traction. 


\section{STUDY OF CHARACTERIZATION OF MATERIALS, IN- SITU TESTS AND FORMULATION OF MASSES}

The materials characterization and the macro-textural analysis of the original rammed earth wall indicated that the earth used on this fabric came from the Alhambra Formation, most likely from the adjoining orchard-garden. The soil showed relative high clay content and had been stabilized with lime, showing also abundant ceramic material, fragments of tile and brick (Figure 9).

Starting from the hypothesis that it was not possible to extract the earth from the original site, it was tried to select material as similar as possible to that of the original rammed earth wall. For this purpose, part of the earth from the partial dismantling was reused (Earth 1, Table 1). Dismantling was performed in order to profile and prepare the surfaces and facilitate the execution of the works (Figure 6). To starting material earth of similar characteristics (Earth 2, Table 1), from a site located in a radius of $240 \mathrm{~m}$ $\left(37^{\circ} 10^{\prime} 46.9^{\prime \prime} \mathrm{N} 3^{\circ} 35^{\prime} 27.1^{\prime \prime} \mathrm{W}\right)$, where earthworks were being carried out for the construction of a new building was added.

To facilitate the mixing and elaboration of the replacement material, the two soils were sieved using a $4 \mathrm{~mm}$ sieve to obtain a homogeneous starting material that facilitates its application, eliminating those remains, organic matter and other elements that were considered unsuitable. However, the discarded material was screened again, recovering different gravel particles that were classified into different fractions (4-6, 6-20 and $20-60 \mathrm{~mm}$ ), being added again to the replacement material depending on the needs of the new formulations (Figure 4).

To these starting materials, sand from a local quarry $(0-4 \mathrm{~mm})$ and a smaller proportion of chamotte or fired ceramic powder were added, all in order to reduce the plasticity of the earth. The chamotte was obtained by manually crushing fragments of Arab tiles (Figure 4), as it appeared in the original wall, obtaining two types of grain size. The largest would be added to the material for rammed earth walls $(0-20 \mathrm{~mm})$, and the finest would be used for filling of holes and superficial reintegrations $(0-6 \mathrm{~mm})$ (Chamotte, Table 1).

In order to improve the stabilization and durability of the replacement material, taking into account the results of the previous laboratory tests described in section 3, different percentages of powdered calcic lime from Estepa Company (Sevilla) were added, as well as linseed oil in a percentage of 2$5 \%$. To check the effects of these additives for volume reintegrations carried out with rammed earth wall, a test specimen of $60 \times 35 \times 20 \mathrm{~cm}$ was prepared (Figure 5). Likewise, application tests were carried out on the renders used for filling voids and surface reintegrations, which were formulated with different dosages and consistencies, and applied to the eroded wall surfaces, incorporating anchoring systems to improve adhesion and performing finishes with different textures, as will be detailed in the next section.

Once the results of the tests carried out on site were analysed and contrasted, the use of linseed oil was ruled out, despite considerably improving the surface resistance. It had caused a slightly whitish colour that it was not acceptable. Likewise, in the case of surface reintegration applications carried out in layers, the oil favoured exfoliation and made adherence of individual layers difficult. Table 1 shows the formulations finally adopted, depending on the different application techniques.

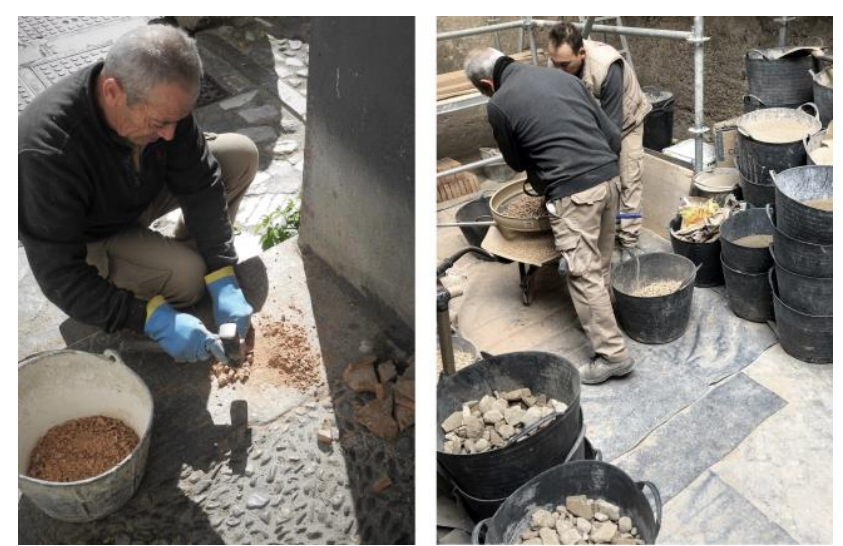

Figure 4. Chamotte preparatory works and development stage of the different masses of earth.
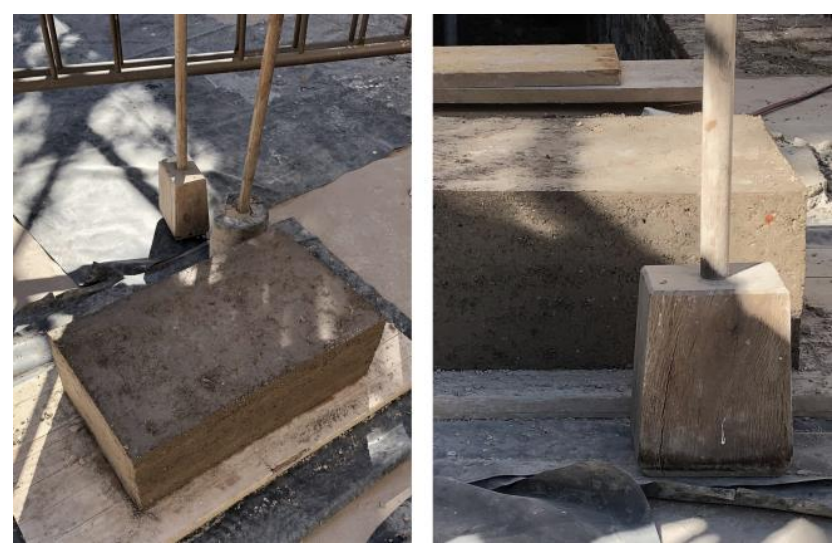

Figure 5. Rammed earth test specimen built in-situ.

\begin{tabular}{l|c|c|c|c|c}
\hline & $\mathbf{m m}$ & $\begin{array}{c}\text { Mass } \\
\mathbf{A}\end{array}$ & $\begin{array}{c}\text { Mass } \\
\mathbf{B 1}\end{array}$ & $\begin{array}{c}\text { Mass } \\
\mathbf{B 2}\end{array}$ & Mass C \\
\hline DOSIFICATION & & $(1: 8)$ & $(1: 8)$ & $(1: 8)$ & $(1: 4)$ \\
\hline Earth 1 & $0-4$ & 4 & 4 & 4 & 4 \\
\hline Earth 2 & $0-4$ & 4 & 4 & 4 & 4 \\
\hline Sand & $0-4$ & 4 & 4 & 4 & 4 \\
\hline Fine gravel & $4-6$ & & & 3 & 3 \\
\hline Gravel & $6-20$ & & 3 & & \\
\hline Coarse Gravel & $20-60$ & 3 & & & \\
\hline Chamotte & $0-6$ & & 1 & 1 & 1 \\
\cline { 2 - 6 } & $0-20$ & 1 & & & \\
\hline Calcic Lime & & 2 & 2 & 2 & 4 \\
\hline
\end{tabular}

Table 1. Mass formulations in the west wall of the Bañuelo.

A. Coarse soil (1:8) used for volume reintegrations carried out using the rammed earth wall technique with pouring and ramming of the mass (Figure 10).

B. Medium and fine soil (1:8) used for the filling of void and superficial reintegrations carried out by vertical ramming, clay lumps, screeding, laying, pressing and mashing (Figure 11).

C. Fine earth mass $(1: 4)$ used for receiving and subsequent soiling of brick in courses and coping (Figure 13). 

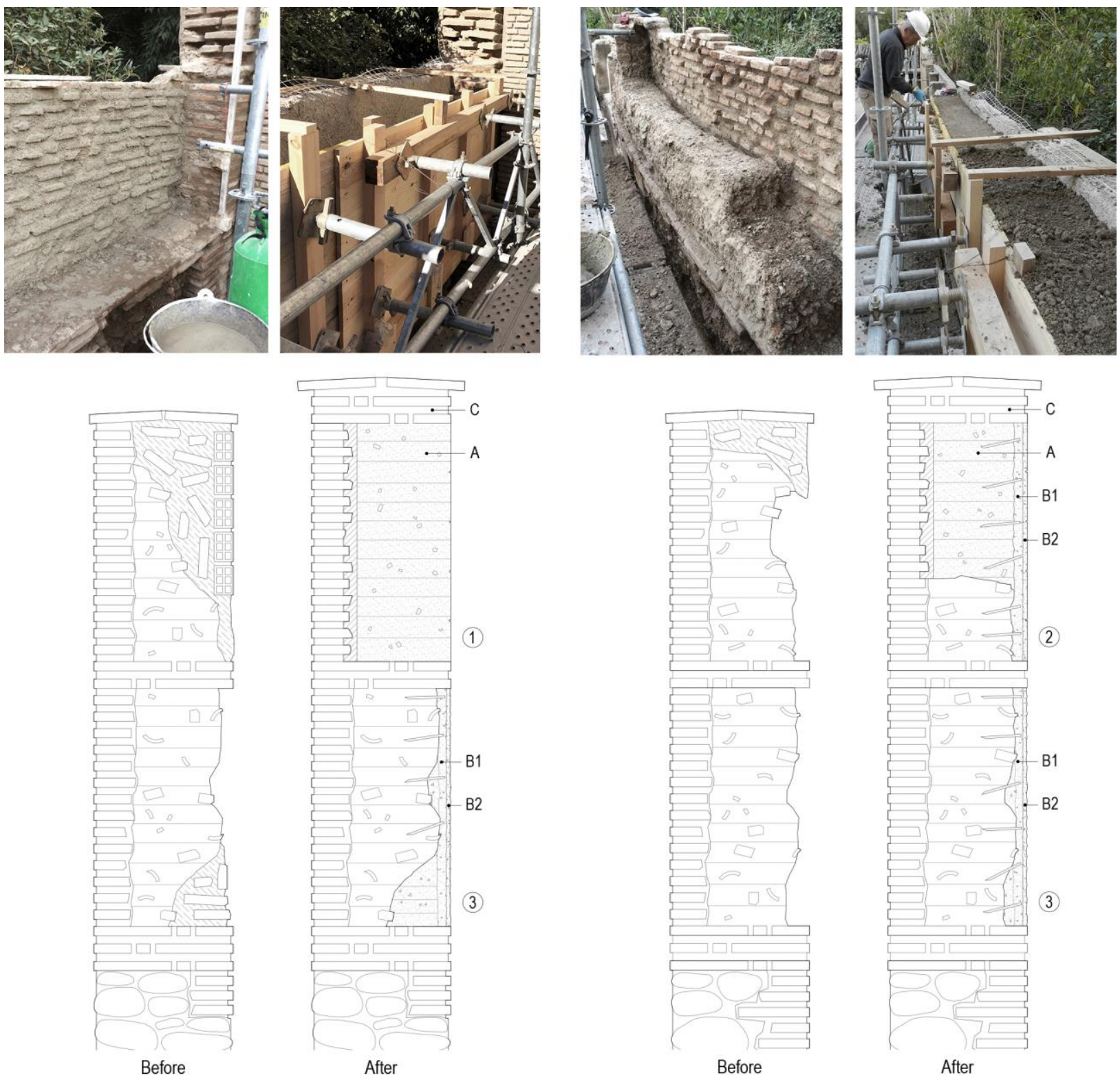

Figure 6. Left: Section pl. 1 / Right: Section pl. 2

Up: State of the wall after dismantling works and installing the wood formworks. Photograph: Bados Navarro S.L. Down: Types of mass: A-B1-B2-C (Table 1) and types of surface finish: 1-2-3 (Table 2).

\section{EXPERIMENTAL CONSOLIDATION OF RAMMED EARTH WALL: THE SETTING UP}

\subsection{Reintegration of volume using the rammed-earth technique}

In the formwork or upper level of the wall, the rammed-earth technique was used to carry out the reintegration of the volume. had previously been repaired with half-foot thick solid brick masonry, which was in good condition of conservation and that served to fulfil the function of the formwork (Figure 6). To reinforce the brick wall, a 1:3 lime mortar reinforced with 5 × 5 $\mathrm{cm}$ fiberglass mesh was applied on the inside, also installing wooden slats on the outside that allowed assembling the formworks. Before installing the formwork, at the north end of the wall the entire original earthen wall was removed as it was in very poor condition and made it difficult to carry out the conservation work.
At the opposite end part of the volume of the wall was conserved, since the erosion was only superficial, allowing, in addition, the development of another intervention technique that reinforced the experimental nature of the work.

For the execution of the new rammed earth wall, two types of formwork were installed. The main one was arranged flush with the brick courses that define the surface plane, and it was built with $24 \mathrm{~mm}$ thick five wooden boards. The secondary formwork was aligned with the remains of the original fabric that remained $27 \mathrm{~mm}$ behind the face plane, which coincided with the thickness of the three-layer wooden board used. Once the works were finished, it was marked the interface between the two formworks on the surface of the new rammed earth fabric, in order to show the different reintegration techniques used. The distinction was signalled by introducing a thin wooden profile on the mass (Figures 8 and 12). 


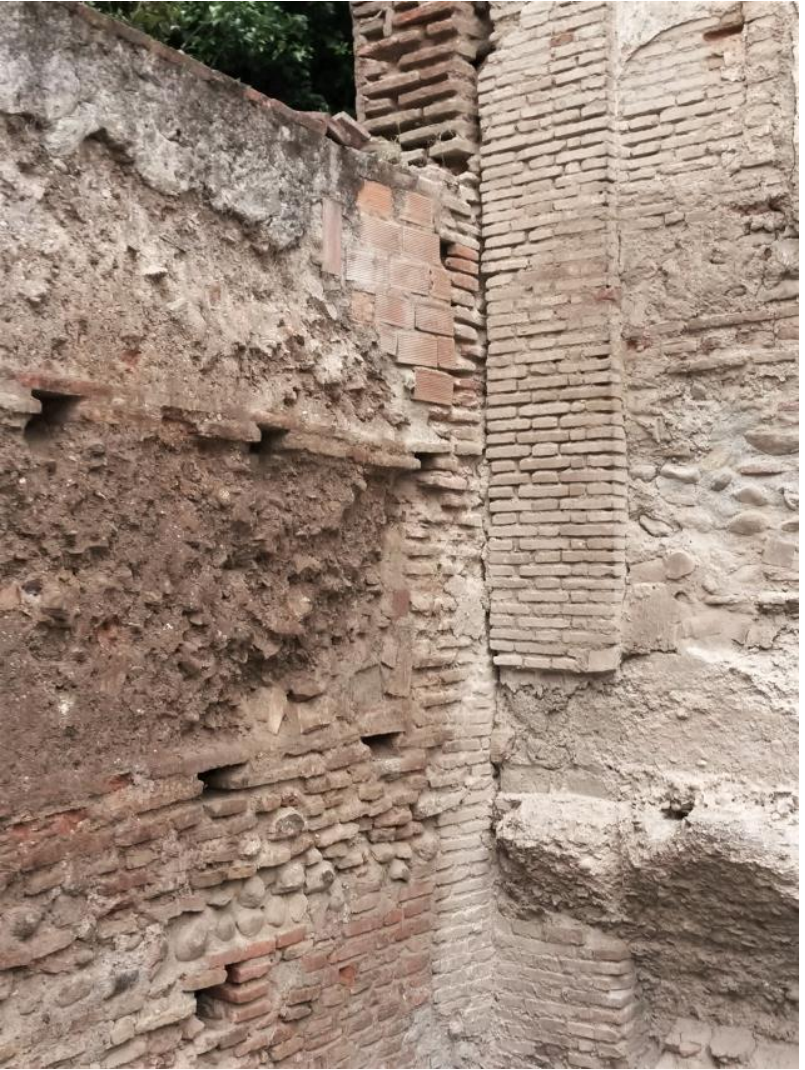

Figure 7. State of preservation of the rammed earth wall before the consolidation works.

No needles stays were placed to support the walls, inserting a threaded steel rod into the putlog hole to close the frame. The boards were supported on the scaffolding through a wooden slat and were bent against it using metal bushings and spindles (Figure 6). Once the two types of formwork were installed, the earth was poured, which was carried out in $10 \mathrm{~cm}$ thick layers, performing the ramming manually with wooden rammers (Figure 10). The soil used was of coarse grain size (Mass A), to which a small amount of water was added to achieve a dry consistency. The degree of compression reached was $70 \%$, which means that $1.43 \mathrm{~m}^{3}$ of dry volume was required to obtain $1 \mathrm{~m}^{3}$ of rammed earth wall.

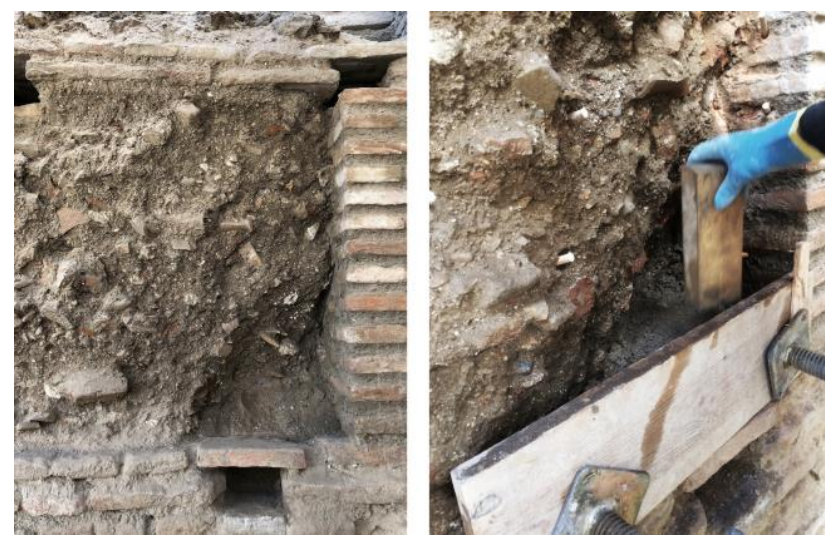

Figure 9. Detail of the previous state of the rammed earth wall with the presence of a void. Punctual formwork and ramming

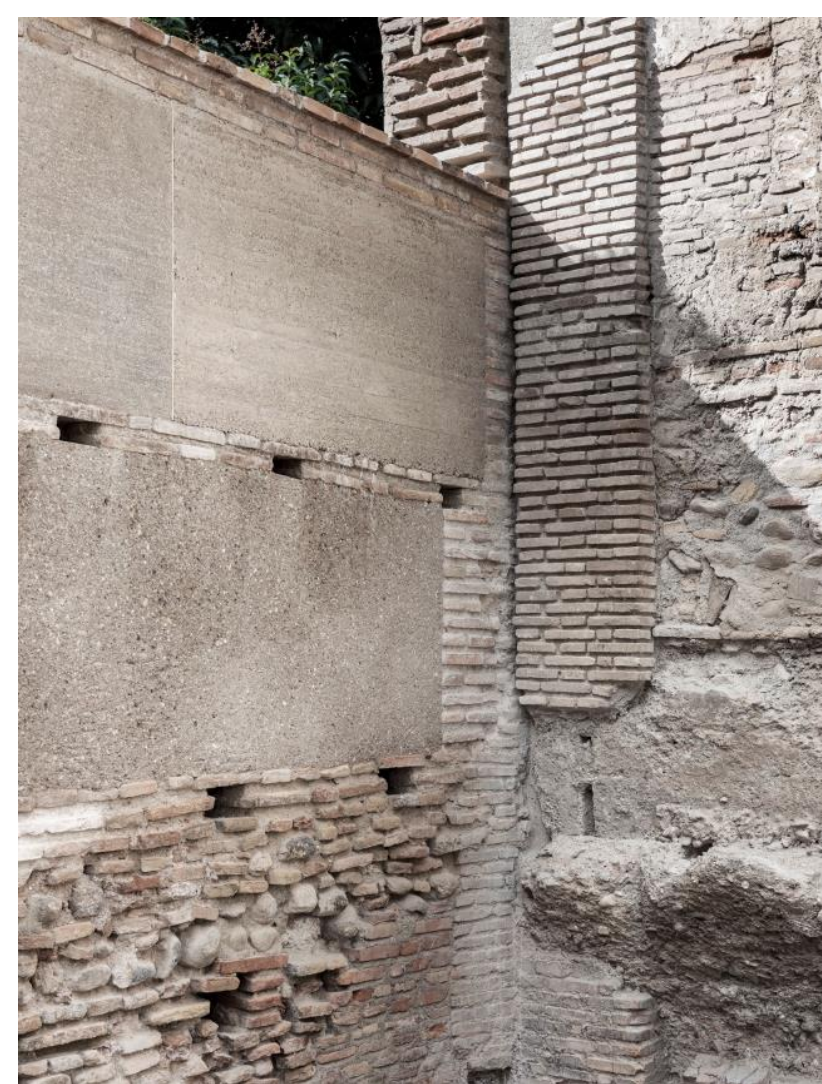

Figure 8. Final state of the rammed earth wall after the consolidation works. Photograph: Cristina García-Zarza.

The surface of the rammed earth wall had two types of finishing depending on the formwork system (Figures 8 and 12). In the case of the main formwork, once the board was removed, no surface treatment was carried out, since it had a relatively smooth texture where the imprints of the wooden boards were manifested (Surface finish 1, Table 2). In the case of the secondary formwork, since it had been submerged with respect to the facing, it was necessary to apply an additional layer. To simulate a similar finishing as described above, light scraping was performed with a round tip palette. Furthermore, horizontal scratches with the help of a metal ruler were made to simulate the imprint of the wooden boards (Surface finish 2, Table 2).
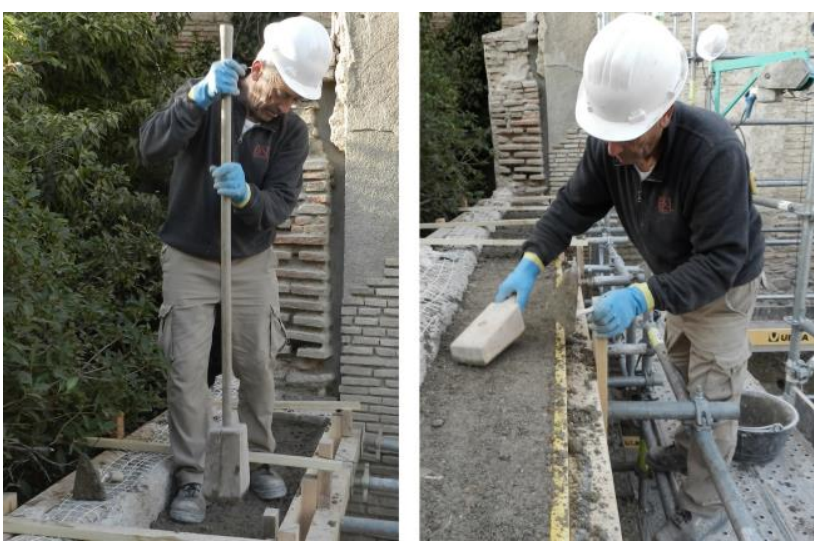

Figure 10. Manual ramming of the mass with the use of a rammer, and taping of the top surface with a hand-rammer. 


\subsection{Filling of voids and superficial reintegration}

Superficial erosions of variable depths (i.e., 2-10 cm) appeared in the lower part of the rammed earth wall, which, in some sectors, showed greater material loss and reached $15-20 \mathrm{~cm}$. The filling of these voids was carried out with soil of medium granulometry (Mass B1), which was rammed vertically with the help of a small wooden formwork adapted to the shape of the void (Figure 9). Minor erosions were filled with clay lumps, using the same type of material rammed horizontally, regularizing the surfaces until they were at a distance of $4-5 \mathrm{~cm}$ from the final finishing face (Figure 11).

The surface reintegration work was carried out in two layers: a $3-4 \mathrm{~cm}$ thick base layer, made with medium grain soil (Mass $\mathrm{B} 1$ ), and a $1.5 \mathrm{~cm}$ thick final layer with a finer soil (Mass B2). The first operation consisted of scraping the surface of the rammed earth wall to create a rough plane that would facilitate the adherence of the applied layer, also installing beech wood pegs $8 \mathrm{~mm}$ in diameter and $150 \mathrm{~mm}$ in length, arranged in staggered, which is nailed to the wall with the aim of improving the anchorage. During the previous tests carried out, a hemp rope was also knotted to improve the assembly, a solution that was ruled out in the final intervention. The application of the soil begins with the execution of vertical guides of the same material that are arranged according to the flatness of the existing wall (screed), accepting deformations and lead losses. The base layer (Mass B1) was applied with a plastic consistency and manually, pressing the clay lumps against the surface and mashing them with the help of wooden dowels. Once the mass had reached the proper consistency and after scraping the surface again, the final layer (Mass B2) was applied also by clay lumps, but with reduced thickness (Figure 11). This surface was finished by deep scraping with a round-tipped trowel to remove the heads from the aggregates and achieve a rough texture (Surface finish 3, Table 2) (Figura 12). This slightly irregular face allows the integration of the new fabric with the structures on which it rests, which featured an important diversity of materials (Figure 8).

\begin{tabular}{|c|c|c|c|}
\hline & $\begin{array}{c}\text { Surface finish } \\
1\end{array}$ & $\begin{array}{c}\text { Surface finish } \\
2\end{array}$ & $\begin{array}{c}\text { Surface finish } \\
\mathbf{3}\end{array}$ \\
\hline TEXTURE: & Smooth & Smooth & Rough \\
\hline LOCALIZATION: & $\begin{array}{l}\text { Upper section } \\
\text { Section pl. } 1\end{array}$ & $\begin{array}{l}\text { Upper section } \\
\text { Section pl. } 2\end{array}$ & $\begin{array}{l}\text { Lower section } \\
\text { Section pl. 1-2 }\end{array}$ \\
\hline $\begin{array}{l}\text { APPLICATION } \\
\text { TECHNIQUE: }\end{array}$ & $\begin{array}{l}\text { Volume } \\
\text { reintegration }\end{array}$ & $\begin{array}{c}\text { Surface } \\
\text { reintegration }\end{array}$ & $\begin{array}{c}\text { Surface } \\
\text { reintegration }\end{array}$ \\
\hline BASE LAYER: & $\begin{array}{c}\text { Mass } \\
\mathbf{A} \\
\text { rammed earth }\end{array}$ & $\begin{array}{c}\text { Mass } \\
\text { B1 } \\
\text { (screeding) } \\
\text { clay lumps } \\
\text { mashing } \\
\text { scraping }\end{array}$ & $\begin{array}{c}\text { Mass } \\
\text { B1 } \\
\text { screeding } \\
\text { clay lumps } \\
\text { mashing } \\
\text { scraping }\end{array}$ \\
\hline FINAL LAYER: & & $\begin{array}{c}\text { Mass } \\
\text { B2 } \\
\text { Clay lumps } \\
\text { laying }\end{array}$ & $\begin{array}{c}\text { Mass } \\
\text { B2 } \\
\text { Clay lumps } \\
\text { laying }\end{array}$ \\
\hline TREATMENT: & $\begin{array}{c}\text { None } \\
\text { Just unmould }\end{array}$ & $\begin{array}{c}\text { Smooth } \\
\text { scraping for } \\
\text { simulation of } \\
\text { rammed earth }\end{array}$ & $\begin{array}{l}\text { Final scraping } \\
\text { for obtaining a } \\
\text { rough texture }\end{array}$ \\
\hline
\end{tabular}

Table 2. Surface finishes in west wall of the Bañuelo.
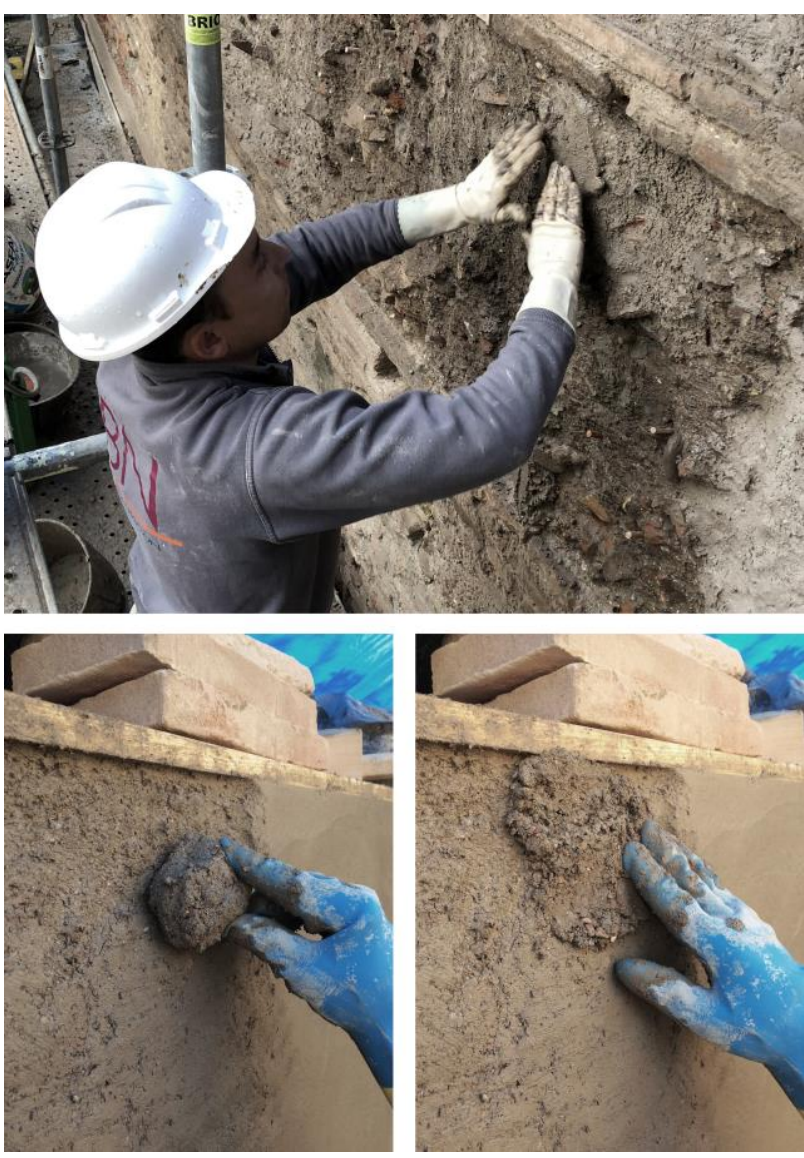

Figure 11. Surface reintegration with clay lumps, applied in the base and the final layer, by manual shaping and mashing.

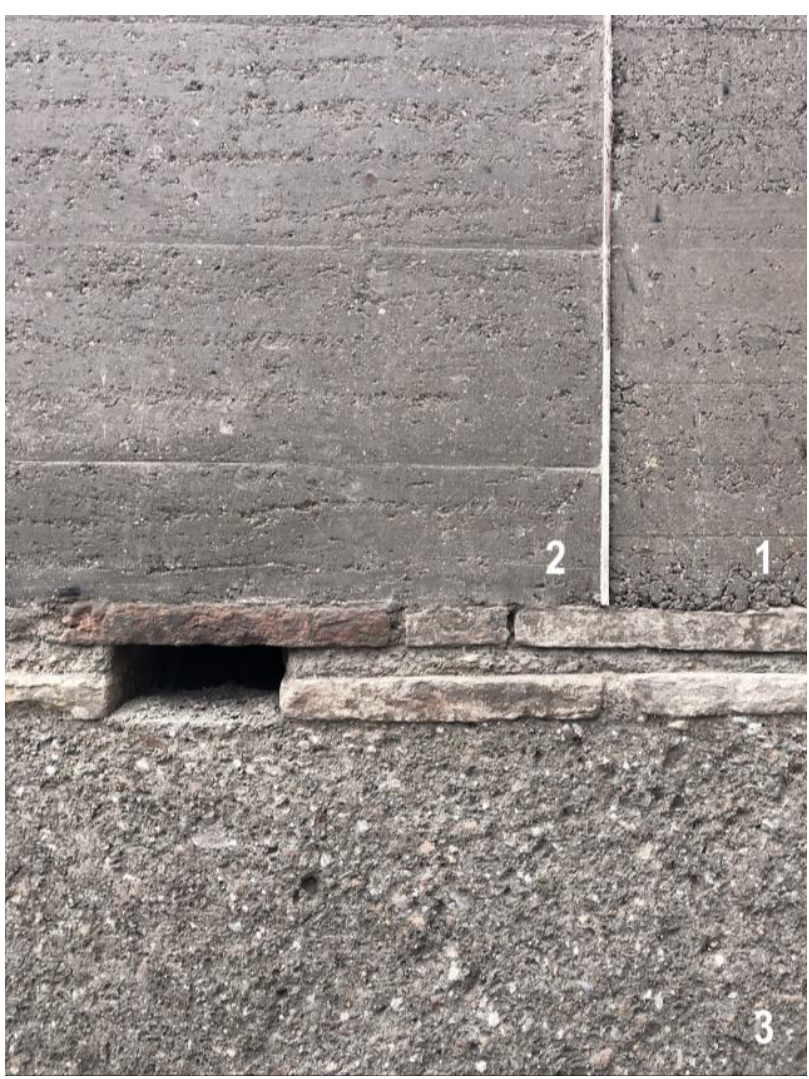

Figure 12. Different types of surface finish: 1-2-3 (Table 2). 


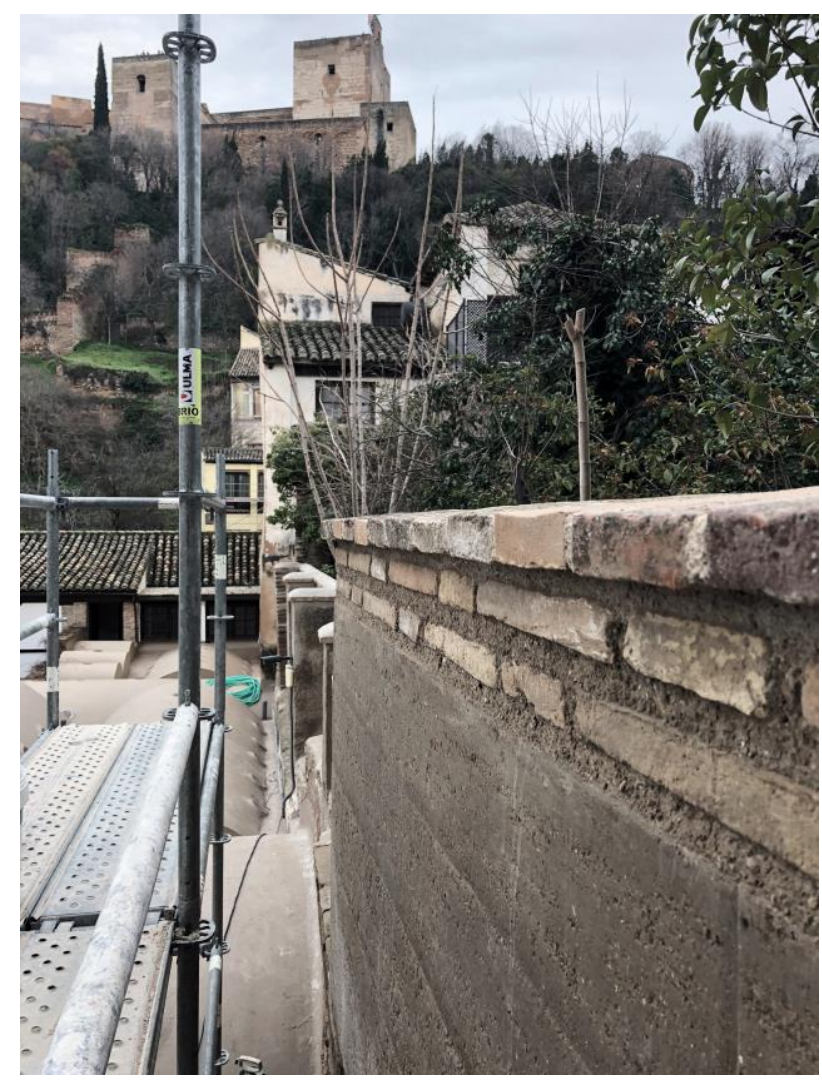

Figure 13. Courses and brick coping as upper auction of the rammed earth wall. At the bottom: the Alhambra of Granada.

\section{CONCLUSIONS}

The restoration of a rammed earth fabric usually presents a characteristic problem due to the difficulty of implementing the original technique, since the installation of the formwork and vertical ramming are not always possible.

This circumstance requires the implementation of alternative on-site techniques, mainly in ramming, macerating or horizontal tightening systems. We must bear in mind that the intergranular cohesion in raw earth is largely due to a pressure exerted on the particles that compose it during the ramming phase. Furthermore, it is important to make a careful selection of the materials and to carry out an adequate adaptation of the masses, in order to modify their cohesion according to the singularities of the installation and the different techniques applied.

In general terms, the mechanical behaviour and durability of the replacement material will be more adequate the more it resembles the original wall, especially in those cases where the vertical ramming technique is reproduced.

Adding additives to the mass can be beneficial, if they come from natural origin. In this sense, stabilization with calcic lime in a percentage lower than $10 \%$ is adequate, considering that it does not behave here as the main binder of the mass, as would be the case of lime concrete fabric or in a lime reinforced rammed earth.

Finally, when intervening on buildings with heritage value, such as the present case, it is especially necessary to determine in detail the surface coating treatment, considering both the intervention criteria adopted and its integration on the general context of the restoration work.

\section{ACKNOWLEDGEMENTS}

We thank Antonio Ruiz Sánchez, head of the Conservation and Protection Service of the Alhambra and Generalife Trust, promoter of the works, as well as the technical staff of the Department of Archaeology and the Department of Restoration. To the archaeologists Luca Mattei and Ana Palanco, who were responsible for the archaeological activities. Analysis was performed at the University of Granada, in the Department of Building Construction, led by Ignacio Valverde-Palacios, and in the Department of Mineralogy and Petrology; we appreciate their collaboration in the laboratory phase. We thank also the companies Bados Navarro S.L. and Julia Ramos Restauración del Patrimonio S.L., for the execution of the works, and Tesela S.L. for the technical-scientific study. Finally, we express our sincere gratitude to Kerstin Elert for their insightful comments, suggestions and review, and Miguel Medrano, David Toledo, Javier Lara and Sara Peñalver for their collaboration in the technical project and the elaboration of the graphic material.

The research developed in parallel to the restoration works and presented in this article, is framed on the R\&D\&I project "RISK-Terra. Earthen architecture in the Iberian Peninsula: study of natural, social and anthropic risks and strategies to improve resilience" (RTI2018-095302-B-I00), a research project funded by the Spanish Ministry of Science, Innovation and Universities.

\section{REFERENCES}

Elert, K., Bel-Anzué, P., Monasterio Guillot, L., Pardo, S., 2019. Performance of alkaline activation for the consolidation of earthen architecture. Journal of Cultural Heritage. https://doi.org/10.1016/j.culher.2019.03.004.

Esbert, R. M., Ordaz, J., Alonso, J., Montoto, M., 1997. Manual de diagnosis y tratamiento de materiales petreos y cerámicos. Colegio de Aparejadores de Barcelona, Barcelona.

Mileto, C.; Vegas López-Manzanares, F., 2017. Proyecto COREMANS: Criterios de intervención en la arquitectura de tierra. Ministerio de Educación, Cultura y Deporte, Madrid.

Orihuela, A.; López-Osorio, J.M., 2019. Knowledge and interpretation processes of the andalusí Bath of el Nogal or Bañuelo (ḥammām al-ŷawza) in Granada, Spain (1832-2019). WIT Transactions on The Built Environment, 191, 97-111. http://dx.doi.org/10.2495/STR.190091.

Orihuela, A.; López-Osorio, J.M., in press. El baño andalusí del Nogal o Bañuelo (hammām al-Ŷawza) en Granada: análisis crítico de un siglo de restauraciones (1919-2018). Informes de la Construcción.

Sharma, G., Wu, W., Dalal, E.N., 2004. The CIEDE2000 colordifference formula: implementation notes, supplementary test data, and mathematical observations. Color. Res. Appl. 30, $21-$ 30. http://dx.doi.org/10.1002/col.20070.

Vissac, A., Fontaine, L., Anger, R., (Laboratoire CRAterreENSAG), 2012. Recettes traditionnelles \& Classification des stabilisants d'origine animale ou végétale. Programme National de Recherche sur la Connaissance et la Conservation des materiaux du patrimoine culturel (PNRCC). Ministère de la Culture et de la Communication, Paris. 